\title{
OVER VERWEERINGSHOLTEN IN DIORIETBLOKKEN OP ARUBA
}

DOOR

\author{
P. WAGENAAR HUMMELINCK
}

(met 8 foto's en 4 figuren)

Wanneer we het aride gebied aan de noordkust van ZuidAmerika bereizen, vinden we vele verschijnselen welke door verschillende auteurs als kenmerkend voor woestijnen of halfwoestijnen worden beschouwd. Enkele van deze verschijnselen, welke optreden in het kwartsdiorietgebied van het eiland Aruba, mogen hier nader worden besproken.

Het is een landstreek welke zeer arm is aan vegetatie, zoodat een gesloten plantendek totaal ontbreekt. De gemiddelde neerslag bedraagt omstreeks $450 \mathrm{~mm}$ per jaar. De natste tijd is van October tot Januari, de droogste tijd van Februari tot Juni; dikwijls valt de regen zoo onregelmatig dat van een regentijd nauwelijks kan worden gesproken. De temperatuur is tamelijk gelijkmatig, het jaargemiddelde is ongeveer $27^{\circ} \mathrm{C}$. De vochtigheid ligt tusschen de 70 en $80 \%$. Bijna het geheele jaar door waait er, met een snelheid van gemiddeld $41 / 2 \mathrm{~m}$ per seconde, een passaat uit het ONO. Bij de denudatie van het terrein moet aan de werking van dezen passaat de leidende rol worden toegekend.

In het diorietgebied van Aruba zijn door de physische verweering „Felsenmeere” ontstaan. Groote en kleine steenhoopen (Foto 2), uit afgeronde diorietblokken met grauwe verweeringskorst opgebouwd, liggen hier over het vlakke landschap verspreid. De grootste opeenhoopingen vinden we bij Ajó, deze zijn 20-30 m hoog en bestaan uit blokken die vaak een middellijn van 5-10 m bereiken. Het grootste diorietblok dat als monoliet kan worden opgevat, hoewel het zich waarschijnlijk nog niet geheel van den ondergrond heeft losgemaakt, ligt bij Casibari (Foto 1). Het is een steenklomp van ongeveer $15 \mathrm{~m}$ hoog en

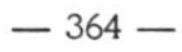


$30-40 \mathrm{~m}$ breed, die door enkele steile, gladwandige breuken is gekloofd. Vele diorietblokken worden door dergelijke breuken doortrokken.

De meeste blokken vertoonen een duidelijke afschilfering, waarbij schaalvormige stukken van meestal $1-3 \mathrm{~cm}$ dikte worden afgespleten ${ }^{1}$ ).

Beide verschijnselen komen veel voor in aride en semi-aride gebieden met granietachtige gesteenten en zijn dan ook herhaaldelijk beschreven en afgebeeld, echter zonder dat er ooit bevredigende verklaringen voor werden gegeven. Dat temperatuursverschillen hierbij een belangrijke rol zouden spelen is nog onbewezen (B la c kwelder, 1933) en, volgens de gegevens die men met laboratoriumproeven, in droog milieu, heeft verkregen, zelfs zeer onwaarschijnlijk (G rig g s, 1936).

Een groot deel van de monolieten die over het diorietlandschap van West Aruba ${ }^{2}$ ) verspreid liggen, vertoonen zeer opvallende ronde holten, van eenige centimeters tot enkele meters doorsnede. Men vindt deze holten, hoewel over het algemeen minder mooi van vorm, ook in nog niet los geprepareerde deelen van den ondergrond, terwijl ze ook in schisteuze deelen van de kwartsdioriet (Foto 4) en in de zeer grofkorrelige hooibergiet voorkomen. $\mathrm{Zij}$ liggen meestal in den $\mathrm{ZW}$.wand, dikwijls ook aan de Z.zijde of aan den W.kant van de blokken, - soms ook wel eens aan de bovenzijde. Slechts bij uitzondering vindt men ze aan de ZO. of O.zijde. Aan de NO., NW. en N.zijde vinden we alleen af en toe enkele ondiepe kommen, welke misschien met deze uithollingen zijn te vergelijken.

De eerste die, voor zoover mij bekend, op dit verschijnsel de aandacht heeft gevestigd, is $\mathrm{V}$ a n $\mathrm{K}$ ool wij k $(1882$, p. 5) geweest. Het viel hem op ,,dat die holen zich alle ten ZuidWesten bevinden; deze omstandigheid leidt tot het vermoeden dat, toen voor eeuwen het eiland Aruba uit zee was opgeheven, een sterke zeestroom uit het Zuid-Westen die granietblokken heeft uitgehold..." Later heeft $\mathrm{M}$ a r t in (1888; I, p. 124; II, p. 48) deze uithollingen nader bestudeerd. Ook volgens hem

1) Polygonale barsten werden nimmer waargênomen.

2) In het diorietgebied van Oost Aruba is de blokvorming veel minder sterk dan in het Westen. Vermoedelijk is dit landschap minder gedenudeerd omdat het veel minder lang geleden zijn beschuttende koraalkalken heeft verloren. Diepe uithollingen werden in dit gebied niet gevonden. 
zijn zij ontstaan door de werking van de branding der zee tijdens de laatste groote transgressie. Naar aanleiding van hun verspreiding teekende $\mathrm{M}$ a r t i n op zijn kaart zelfs het verloop van de $\mathrm{N}$. en de O. grens van een ,alte Meeresbucht”: bezuiden de Alta Vista en den Kristalberg en bewesten den Arie Kok en de Jamanota. In lateren tijd vinden we deze opvatting terug bij D u y f jes (1911, p. 273) en nog in 1932 gaf We st e r m a n n (p. 121) enkele bijzonderheden in aansluiting aan dezelfde zienswijze. - Het komt mij echter voor dat deze holten met een vroegere overstrooming van het eiland niets te maken hebben, maar dat zij daarentegen geheel zijn toe te schrijven aan een vorm van physische verweering welke heden ten dage nog actief is. Het zijn vooral de volgende waarnemingen geweest die mij deze overtuiging hebben gegeven.

le. Het holenvormende proces maakt holle vormen met scherpe randen; de randen van eventueel aanwezige spleten worden niet afgerond maar juist uitgeprepareerd. Het maakt holten die soms slechts door middel van kleine, scherprandige openingen met de buitenwereld samenhangen (Foto 5-8, Fig. A-D) ${ }^{1)}$.

2e. Er zijn geleidelijke overgangen tusschen het prachtigste uitgeholde blok en een slechts weinig carieuzen wand (Foto 3, 5, $7,8)$. We krijgen den indruk, dat de buitenste gesteentelaag het meeste weerstand tegen uithollen biedt; is deze laag eenmaal doorbroken, dan gaat de vergrooting van het gat, in verhouding tot het wegvreten van deze buitenste schaal, zeer snel in zijn werk. Een samenvloeien met naburige gaten schijnt zoo lang mogelijk te worden vermeden (Foto 4, 5, 8; Fig. A, C.). Op den duur blijft er van het massieve blok nog slechts een schil over, die tenslotte meestal door omvallen of door andere oorzaken in stukken breekt.

3e. Soms worden blokken, die tevoren reeds uithollingen vertoonden, door breuken gekloofd. In dat geval vinden we wel eens dat door de kanteling van het blok oudere uithollingen in hun ontwikkeling zijn geremd en dat zich, geheel aangepast aan de ligging en den vorm van de nieuwe deelen, nieuwe uithollingen hebben gevormd (Foto 5, 6; Fig. A-C).

4e. In sommige gaten, die moeilijk door den wind kunnen

1) De opening van den uitgeholden monoliet welke door W e s t e r$\mathrm{m}$ a n n (1932, Pl. I, 3) wordt afgebeeld, was vroeger veel grilliger dan nu; een groot deel van den overhangenden rotswand (ca 4-5 m²) is er afgebroken en ligt nu in stukken op den grond. 
worden schoongeblazen, vinden we kleine, slechts enkele $\mathrm{mm}$ dikke schilfers. Dergelijke schilfers kunnen dikwijls met een scherp voorwerp van den binnenwand van het gat worden gelicht.

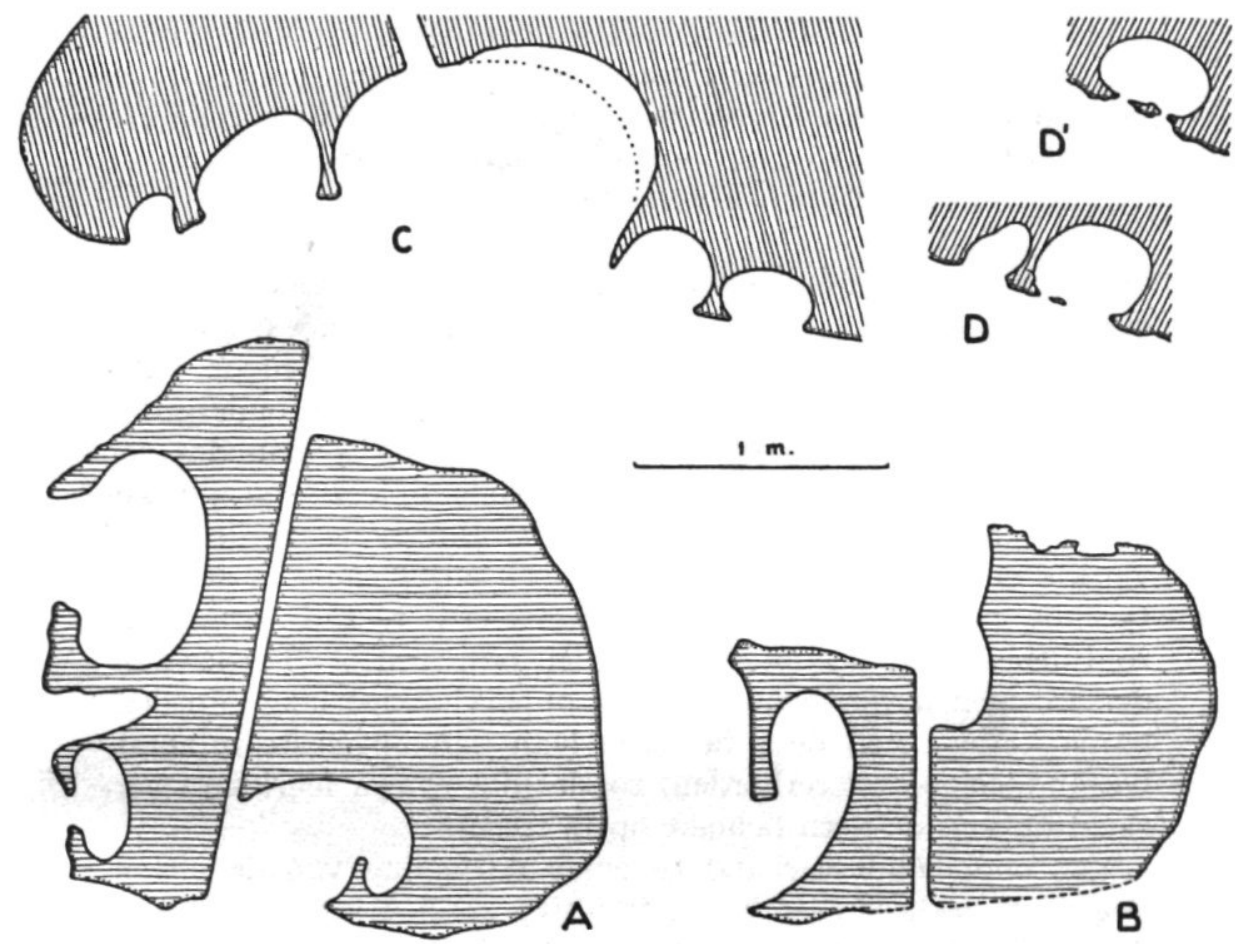

FIg. A. Doorsnede in horizontale richting van het op Foto 6 afgebeelde diorietblok (iets gewijzigd).

FIG. B. Doorsnede in verticale richting van hetzelfde diorietblok.

FIg. C. Doorsnede in horizontale richting van een deel van het, op Foto 5 afgebeelde diorietblok (het afgebroken linkerdeel in oorspronkelijke positie teruggebracht). De stippellijn geeft de veronderstelde ligging aan van den wand van de grootste uitholling tijdens het afbreken van het linker deel.

FIG. D. Doorsnede in horizontale richting van de beide holten welke op Foto 7 zijn afgebeeld. D' ligt op iets hooger niveau, hier is alleen het rechter gat getroffen.

(Van fig. A, C, D en $\mathrm{D}^{\prime}$ is de bovenkant naar het $\mathrm{N}$. gericht).

5e. De uithollingen zijn niet aan een bepaalde hoogte gebonden; we vinden ze b.v. zoowel bij Santa Cruz (op $25 \mathrm{~m}$ boven zee) als op den top van den Kristalberg $(80 \mathrm{~m}$ ) en op den Hooiberg (op $120 \mathrm{~m}$ ). Een optreden in gordels werd niet waargenomen. 
Het verschijnsel kan misschien worden vergeleken met de vorming van de losliggende „Hohlblöcken” van ongepantserde gesteenten, welke W a l th e r (1932, p. 168) van de Egyptische woestijn vermeldt en van nog enkele andere holten welke door hem zijn afgebeeld. Ook de „Dew-holes” in de graniet van het aride gebied van NW. Peru, welke door B o s w o r t h (1922, fig. 60,61) zijn afgebeeld, schijnen verwante vormingen te zijn en misschien is dit ook het geval met de ,pockets" die door B l a c kwe lde r (1929) van het woestijngebied in het $Z W$. van de Vereenigde Staten worden vermeld.

Van gaten, die onder invloed van de insolatie, zouden zijn ontstaan door de verweerende werking van de in het gesteente circuleerende oplossingen, kan zeker niet worden gesproken. Immers, we vinden de mooiste verweeringsholten in de vaste gesteentekernen welke den samenhang met den ondergrond geheel of nagenoeg geheel hebben verloren en waarin dus een voortdurende aanvoer van zouthoudende oplossingen uit het onderliggende gesteente onmogelijk is. Bovendien is de wand van de holten op het oog steeds versch en, evenals de schilfertjes die zich ervan losmaken, onverweerd, terwijl van eenige zoutuitbloei nimmer iets kon worden bespeurd. - Eerder zouden we mogen verwachten dat de oppervlakkige laag van deze harde kernen zich door het neerslaan van opgeloste minerale bestanddeelen zou verharden, zonder dat er een merkbare verzachting van de kern behoeft op te treden.

Een oorzakelijk verband tusschen de ligging van de uithollingen en de heerschende windrichting zouden we kunnen vinden, indien we aannemen dat de verharde buitenlaag het dikste is op het, den wind toegekeerde gedeelte van het gesteente en dat het uithollende proces alleen zou optreden op plaatsen waar deze moeilijk aantastbare korst dun is of ontbreekt. Indien we verder nog zouden mogen aannemen dat de wanden van de holten langer vochtig blijven dan de buitenkant van het gesteenteblok (dat steeds aan den directen invloed van wind en zon is blootgesteld) en dat vochtigheid de afschilfering bevordert (B l a c kw e 1 d e r, 1929), dan zou hierdoor zelfs het snelle invreten van de uithollingen kunnen worden verklaard. - In werkelijkheid is ons echter van de werking van dit uithollende verweeringsproces nog niets met zekerheid bekend en in hoeverre de verschillende veronderstellingen in deze richting juist zijn laat zich nu nog niet beoordeelen. 


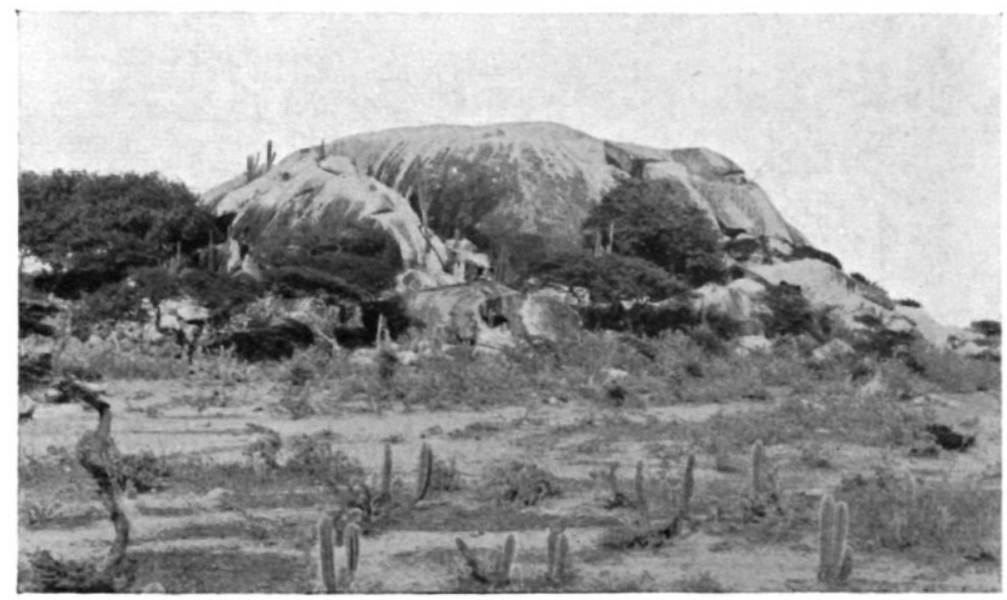

Foto 1. Diorietkopje bij Casibari, Piedra Plat, Aruba, $40-50 \mathrm{~m}$ boven zee; gezien vanuit het $\mathrm{ZW}$. Centrale deel ongeveer $30 \times 30 \times 15 \mathrm{~m}$ hieromheen blokken met uithollingen op het ZZW. (Het centrale deel vertoont dergelijke uithollingen niet.)

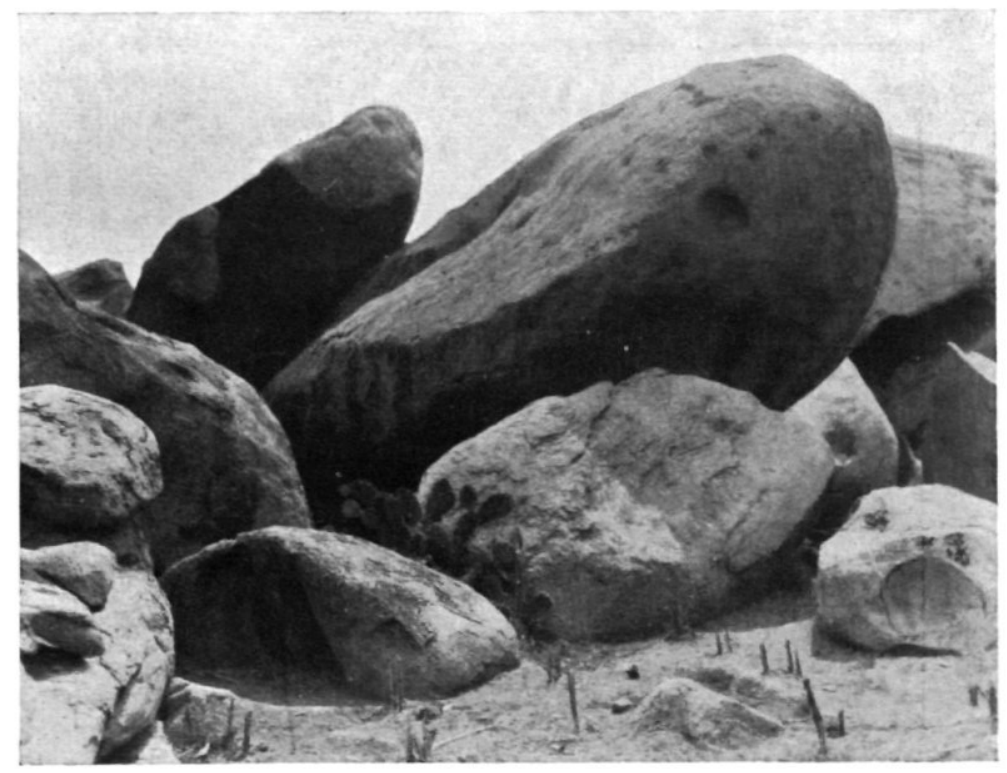

Foto 2. Diorietblokken bij Calabas, Aruba, $40-50 \mathrm{~m}$ boven zee, met duidelijke afschilfering. (Juli 1930; alle andere foto's December 1936). 


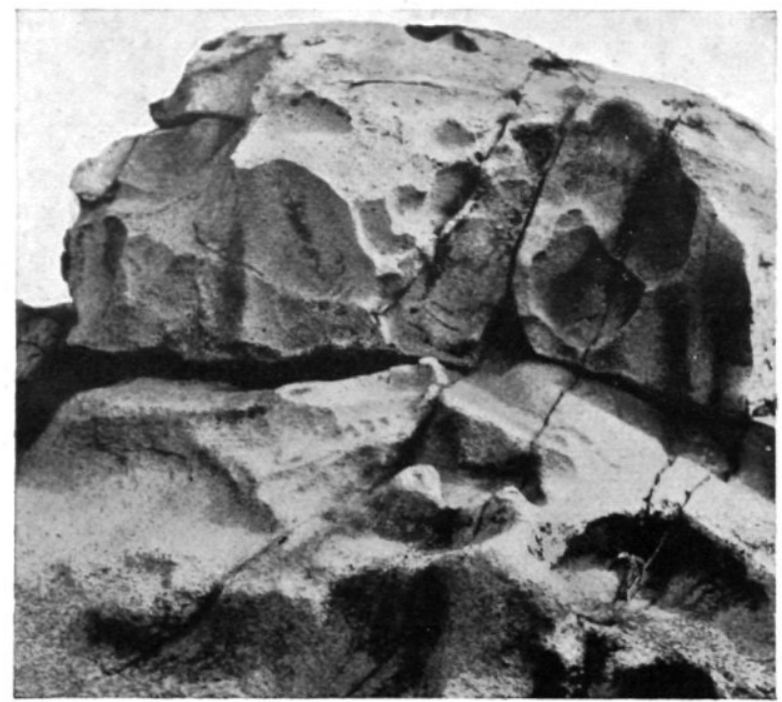

Foto 3 Aangevreten $\mathrm{ZW}$.wand van een diorietkopje, $250 \mathrm{~m}$ ONO. van de kerk van Santa Cruz, Aruba, $35 \mathrm{~m}$ boven zee. Losse bovenstuk $2 \times 21 / 4 \times 1 \frac{1}{4} \mathrm{~m}$.

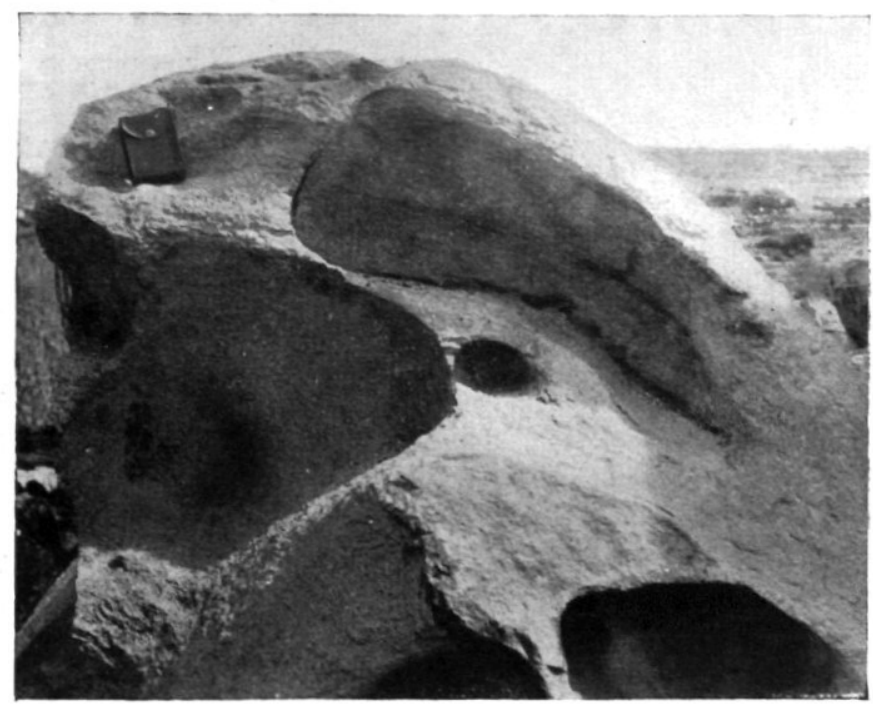

Foto 4. Uithollingen aan den ZW.kant van een schisteus diorietkopje, $250 \mathrm{~m}$ NNW. van de kerk van Santa Cruz, $40 \mathrm{~m}$ boven zee. Holte rechts-boven $110-120 \times 30-35 \times 45-50 \mathrm{~cm}$. 


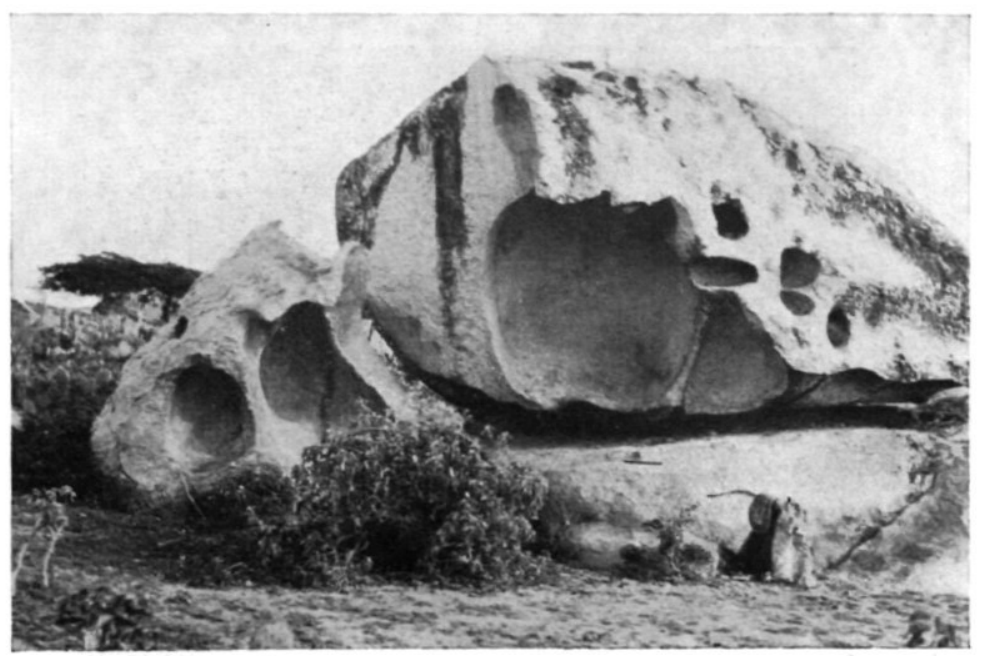

Foto 5. Uithollingen in den Z. en ZW.wand van een gebroken diorietblok, $200 \mathrm{~m}$ O. van de kerk van Santa Cruz, Aruba, $30 \mathrm{~m}$ boven zee. Blok (incl. afgebroken stuk) $6 \times 3 \frac{1}{4} \times 3^{1 / 4} \mathrm{~m}$; grootste uitholling (gereconstr.) $165 \times$ ca $125 \times$ ca $150 \mathrm{~cm}$ (Fig. C).

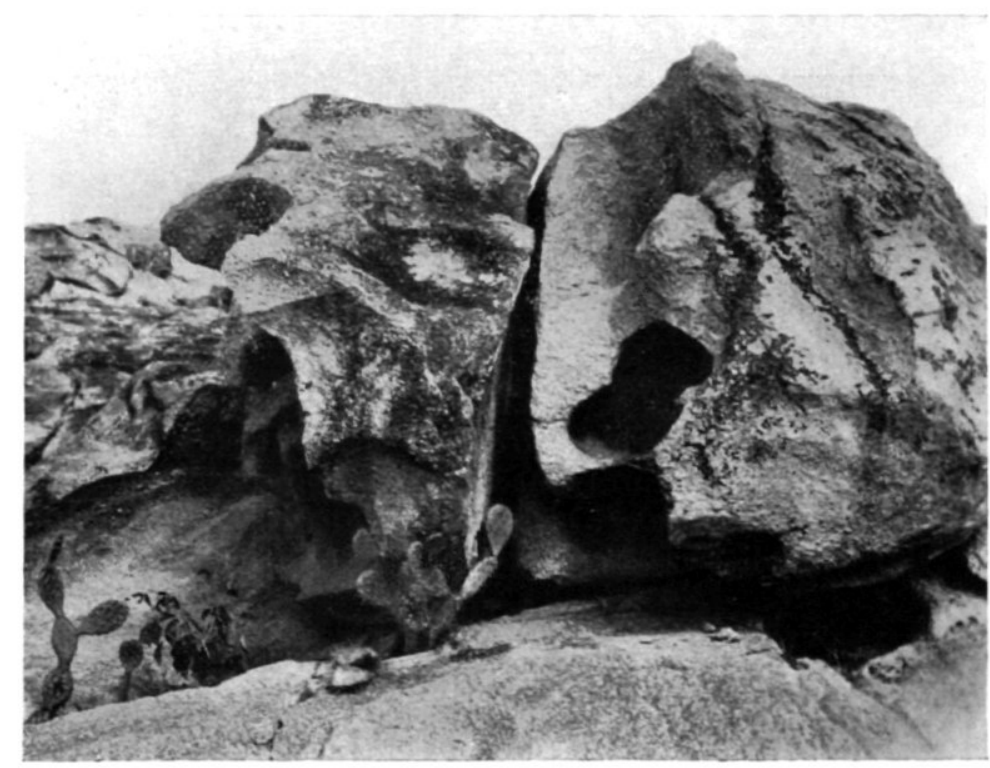

Foto 6. Uithollingen op het $\mathrm{ZW}$. en W. in een gebroken diorietblok, $500 \mathrm{~m}$ NNW. van de kerk van Santa Cruz, $35 \mathrm{~m}$. boven zee. Rechter deel ca $3 \times 4 \times 3 \mathrm{~m}$ (Fig. A, B.). 


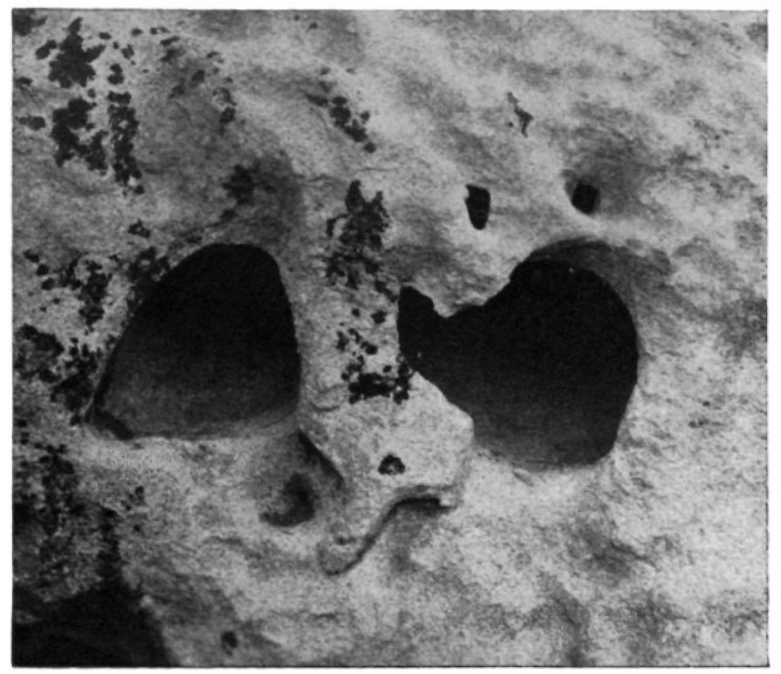

Foto 7. Twee uithollingen in den ZZW.wand van een groot diorietblok, eveneens te zien op foto 8 , rechts. Linker holte $33 \times 38 \times 28 \mathrm{~cm}$; opening $30 \times 28 \mathrm{~cm}$. Rechter holte $53 \times 46 \times 47 \mathrm{~cm}$; openingen $38 \times 33 \mathrm{~cm} .5 \times 7 \frac{1}{2} \mathrm{~cm} .5 \quad 4^{1 / 2} \mathrm{~cm}$ (Fig. D, D'.).

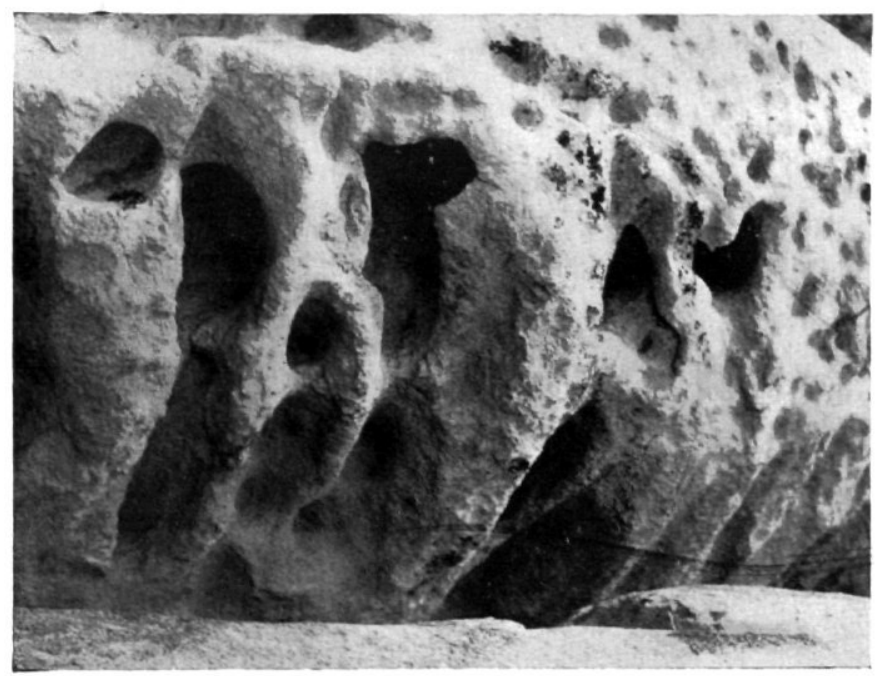

Foto 8. Carieuze ZZW. en ZW.wand van een groot diorietblok, $250 \mathrm{~m}$ NNW. van de kerk van Santa Cruz, Aruba, $40 \mathrm{~m}$ boven zee. 


\section{Ueber Verwitterungshöhlen in Diorit- blöcken a uf Aruba.}

Im Quarzdioritgebiet der Westindischen Insel Aruba haben die abtragenden Kräfte eines tropischen Steppenklimas Felsenmeere geschaffen. Viele Monolithen zeigen an Ihrer SW., S. oder W. Seite (d.i. im Windschatten des ONO. Passates) auffallende rundliche Aushöhlungen, von einigen Zentimetern bis einigen Metern im Durchschnitt. Nach Martin und Westermann hat die Brandung des Meeres zur Bildung dieser Aushöhlungen Anlass gegeben. Der Meinung des Autoren nach sind sie aber einer bestimmten Verwitterungsform (einer feinen Abschuppung) zuzuschreiben, welche bis jetzt immer noch aktiv ist. Für diese Auffassung sprechen: 1. Das oftmalige Vorkommen runder Höhlen mit einer engen, scharfrandigen Oeffnung. 2. Das nicht auf bestimmten Horizonten beschränkt sein der Aushöhlungen. 3. Das Vorhanden sein kleinerer Schuppen in den Höhlen selbst. 4. Das Vorkommen von Aushöhlungen welche entstanden sind, nachdem Blöcke die vorher bereits Aushöhlungen besassen, durch Spalten zerklüftet wurden.

\section{Literatur}

B l a ckwelder, E., 1925, Exfoliation as a phase of rock weathering; Journ. Geology 33 p. 793-806.

B l a c k w e l d e r, E., 1929, Cavernous rock surfaces of the desert; Amer. Journ. Science (5) 17 p. 393-399.

B l a c k w e ld e r, E., 1933, The insolation hypothesis of rock weathering; Amer. Journ. Science (5) 26 p. 97-113. (literatuur!)

B o s w o r t h, T. O., 1922, Geology of.... the North-West part of Peru.

B r a a k, C., 1935, Het klimaat van Nederlandsch West-Indië (The climate of the Netherlands West Indies). Kon. Ned. Meteor. Inst. No. 102, Meded. Verhand. 36.

D u y f j e s, G., 1911, Het landschap van Aruba; Neerlandia 15 p. $272-274$.

G rig g s, D. T., 1936, The factor of fatigue in rock exfoliation; Journ. Geology 44 p. 783-796.

M a r t i n, K., 1888, Bericht über eine Reise nach Niederländisch West-Indien, I. Land und Leute, II. Geologie.

V a n K o ol wij k, A. J. 1882, De Indianen Caraïben van het eiland Aruba (West-Indië); Tijdschr. K. Ned. Aardr. Gen. 6 p. 222-229.

W a 1 t h e r, J., 1924, Das Gesetz der Wüstenbildung, ed. 4.

W e s t e rm a n n, H., 1932, The Geology of Aruba.

W e sterm a n n, H., in: Geol. \& Mijnb. 1931 p. 145; Leids. Geol. Meded. 1931 p. 713 ; Natuur en Mensch 1934 p. 52 ; R e a 1 i n o, Onze Eilanden in Ned. W. Indië 1931 p. 67. 